\title{
Interpreting the perceptions of authenticity in virtual reality tourism through postmodernist approach
}

\author{
Bo Wendy Gao ${ }^{1}$. Chris $\mathrm{Zhu}^{2,3}$ (1) Hongmei Song ${ }^{3}$. \\ lanthe M. Belisle Dempsey ${ }^{4}$
}

Received: 9 June 2021 / Revised: 30 January 2022 / Accepted: 5 February 2022 /

Published online: 20 February 2022

(c) The Author(s), under exclusive licence to Springer-Verlag GmbH Germany, part of Springer Nature 2022

\begin{abstract}
Based on the authenticity theory and limited extant research on virtual reality (VR) tourism experience, this study aims to extend authenticity theory by focusing on perceptions of authenticity from postmodernist approach and developing a theoretical framework for tourists participating in VR tourism experience. In-depth interviews were conducted with 28 respondents, and thematic analysis was adopted to analyze the data. Through inductive and deductive data analysis, three main themes are extracted, and six sub-themes are generated, helping to form a framework of authenticity in VR tourism. The findings contribute both to be authenticity theory and VR tourism implication.
\end{abstract}

Keywords Authenticity · Virtual reality tourism · Postmodernism approaches · Thematic analysis

Chris Zhu

T19091110203@cityu.mo

Bo Wendy Gao

wendy.gao@connect.polyu.hk

Hongmei Song

T19092100135@cityu.mo

Ianthe M. Belisle Dempsey

ianthe@alumni.ilstu.edu

1 Faculty of International Tourism and Management, City University of Macau, Avenida Padre Tomás Pereira, Taipa, Macao

2 School of Tourism Management, Macao Institute for Tourism Studies, 6G4X+Q3M, Taipa, Macao

3 Faculty of International Tourism and Management, City University of Macau, Avenida Padre Tomás Pereira, Taipa, Macau SAR, China

4 School of Theatre and Dance, Illinois State University, Chicago, IL, USA 


\section{Introduction}

The term 'authenticity' has always been a concept difficult to define, especially in the context of tourism experience. Three approaches toward authenticity were identified as objectivist, constructivist, and postmodernist (Wang 1999) which led to three different types of authenticity: objective, constructive and existential (Belhassen et al. 2008a; Dueholm and Smed 2014; Shehade and Stylianou-Lambert 2020).

The concept was under seemingly unresolvable scrutiny even before the technology brought us virtual reality (VR) and augmented reality (AR). The objectivist approach has its refutation built in: could a centuries old artifact away from its habitat displayed in a glass cabinet in a modern museum be considered objectively authentic? What about a display of intricately produced replicas of such treasures? Would those replicas become objectively authentic when the tourists view and accept them as being so? (MacCannell 1973). The constructivist approach proposes authenticity as pluralistic social process, 'constructed and negotiated by its subjective audiences' (Dueholm and Smed 2014; Shehade and Stylianou-Lambert 2020). However, could such subjective perception be perceived as authenticity, while it is suggesting that there should be almost as many interpretations of authenticity as there are tourists?

The deconstructionist attempts to define authenticity, the postmodernist approach, starts with rejecting inauthenticity as a problem that needs a solution. It introduces the idea of 'hyperreality' as a simulated experience that satisfies the desire for the real (Rickly-Boyd 2012). In the postmodernist approach, the borders that separate the copy from the original are erased and authenticity is decided by the quality of the offering and its ability to convince the audience. In this way of thinking, existential authenticity is described as an emotional and creative experience which is, in our milieu, defined by the tourist. Existential authenticity, therefore, is 'an existential state in which one is true to one's real self in a given moment' (Belhassen et al. 2008).

The prior studies were mainly based on the aspects of destinations, such as souvenir authenticity, food authenticity, work authenticity, and brand authenticity (Chhabra et al. 2003; Fu 2019; Lunchaprasith and Macleod 2018; van den Bosch and Taris 2014). Along with the technology development, VR has been adopted by the tourism industry and attracted the researchers' attention (Guttentag 2010; Tussyadiah et al. 2018). As the line between reality and virtual becomes more and more blurred, VR technology provides a new platform to tourists interested in both needs of physical immersion and psychological presence (Izard et al. 2018; Jung and Tom Dieck 2017). Visualization, immersion, and interactivity are considered as the main elements in virtual reality tourism (Guttentag 2010). Visualization means neither mobile-based nor computer-based VR products provide the $3 \mathrm{D}$ model, images, and other visual environment components to make the tourists feel fully involved in the 'real-world' in tourism. Immersion means bodily feelings; physical phenomena created by VR technology can enrich the tourists' senses, including internal and external emotions. Therefore, interaction 
is a critical factor in understanding VR applications in tourism. VR technology enables tourists to experience tourism destinations in a virtual world that are very close to real-world attractions. Therefore, this study discusses the perceptions of authenticity in VR tourism through the postmodernist approach.

Postmodernism is an intellectual approach that is centered on the reality of the individual. Its main attribute is the denial of any statement that claims to be true of all people. Applied to this study, a postmodern approach would deny any collective definition of reality, which is the only way to consider the 'reality' of VR. What is presented in digital fashion cannot have a shared definition of authenticity. It is dependent on the reaction of the individual. Any kind of consensus is also relative. Even if all respondents agreed that a particular presentation is 'authentic', it doesn't make it universally authentic. It just means that to that particular group it appeared as authentic (Shehade and Stylianou-Lambert 2020).

There are two production methods for the content design of VR tourism, one is holographic photography specific places, and the other is computer-generated $3 \mathrm{D}$ environment—called a 'virtual environment' (VE), such as underwater adventures. In this regard, VR tourism is reconstructed and inauthentic. However, tourists still prefer to discuss the perceived authentic feelings of tourism products in VR presentations. Therefore, the interpretation of the authenticity feelings of VR tourism should be based upon the postmodernist approach as the boundary between the copy and the original creation is blurred, and tourists are mainly searching enjoyment (Wang 1999). Authenticity issues in this study refer to how the interviewees interpret the authenticity of VR content based on their perceptions of the world and places through different media, as well as their past experiences. Authentic feelings refer to their experience in a VR environment. Cause we all know that the VR environment is a virtual world, especially some products are 3D computer-generated, they knew it is fake, but the feeling is real, this feeling comes from the sense of presence and immersion of the main experience created by VR.

Based on the aforementioned research gap, the present study aims to explore the interpretation of the perceived authenticity in VR tourism through qualitative study. In bridging the research gap between authenticity theory and VR tourism, the contributions of this study can enrich the authenticity theory by applying it to information and communication technologies (ICT). Second, by exploring the relationship between authenticity orientation and authenticity experience in the VR tourism environment, the study provides a conceptual framework for the perceived authenticity in VR tourism so that future research can be based upon the study's findings. The results of this study provide inspiration for destination managers to develop and improve VR product functions and stimulate marketing changes.

\section{Literature review}

\subsection{Virtual reality in tourism}

Virtual reality (VR) as an essential Information and Communication Technology (ICT) has been amply applied in tourism industries (Benckendorff et al. 2019; 
Lin et al. 2019; Poux et al. 2020; Simon and Greitemeyer 2019). VR through creating immersive environments is beneficial and meaningful for tourism and hospitality sectors, enabling tourists to experience the virtual environment through virtual walkarounds and pre-arrival experiences of facilities (Lin et al. 2020). According to Guttentag's (2010) review on VR application in the tourism sector, first, VR can contribute to tourism planning and management, which can serve as a useful tool for communicating tourism plans to members of an appropriate group or community and possibly receiving input from such individuals. Second, VR can be used to plan and manage a destination just as well as it can be used to market a destination. For example, Huang et al. (2016) applied VR technology to create a virtual marketing platform to examine the tourist behavior based on the TAM model, indicating VR is an auxiliary method for tourism practice. In addition, VR is also amply applied in tourism education and heritage preservation (Bec et al. 2019; Yung and Khoo-Lattimore 2019).

VR is defined as a technology that can immerse the tourist's enjoyment in a virtual or artificial environment (Wagler and Hanus 2018). VR technology in a tourism context is divided into mobile-based and computer-based (tethered) VR (Tussyadiah et al. 2018). According to Tussyadiah et al.'s (2018) review, mobile-based VR - such as untethered headsets - is most practical for daily use and mobile systems' main advantages are a low financial barrier to entry and the proliferation of consumer smartphone devices that can display VR content to some degree. However, the convenience of mobile-based VR comes at the expense of higher processing capacity, limiting its ability to display True 3D material. Papachristos et al. (2017) further explains why mobile-based VR has rarely been used in tourism in recent years due to its low cost, low refresh rate, and low presentation characteristics. Instead, tourism sites widely use the second VR- tethered VR.

The second category, tethered (computer-based) VR, has coupled headsets that usually rely on connection to a personal computer (PC) to provide graphics information and processing power. The computer-based VR advantage of the tourism experience environment includes visual, auditory, and tactile senses. In the tourism experience, tethered VR provides 3D models, stories, and some interesting experience projects. By setting the virtual content design such as realistic scenery effects and high degrees of the natural site provides the "real" natural environment with tourists, especially when tourists have previous physical experience in the real destination site, the authentic feelings will become stronger based on comparison with the real and virtual presentation. Moreover, the tourism experience is influenced by stored photos, haptic devices, and exoskeleton devices (Tussyadiah et al. 2018). Therefore, tourists could realistically experience the simulated environment as VR instantly tricks their minds through VR-created sensory stimuli (Wei 2019). From this perspective, VR is advantaged for its 'real' presentation. In other words, the acceptance level is decided by VR' authentic' degrees. Thus, rethinking how to improve authentic feelings on VR experience is meaningful and necessary. 


\subsection{Authenticity}

\subsubsection{Modernist authenticity}

The development of authenticity research can be simply divided in two stages which are modernist and postmodern authenticity. Modernism simplifies the world with a unified social order in which there is an absolute dichotomy. That is, in this order, there is an absolute dichotomy between woman and man, East and West, subject and object, real and false, everyday matters and particular experiences (Kim et al. 2018). Current research regarding modernist authenticity mainly divides three categories of authenticity, namely objective, constructive, and existential authenticity (Reisinger and Steiner 2006; Steiner and Reisinger 2006; Wang 1999). Objective authenticity is defined as it could be determined by testing or assessing it according to certain standards, referring to an object's pure, original, and genuine version (Chhabra 2010). It refers to the truthfulness, accuracy, or authenticity of physical objects, including life processes, activities, artifacts, etc. (Lau 2010). Objective authenticity comes from the originality of tourism objects (Belhassen et al. 2008), or the historical accuracy of events and the original locations where particular events took place. Meanwhile, VR stimulates tourist objects and improves their characteristics through technology restoration and scenery creation. From this perspective, adding some functions to VR presentations regarding tourism objects enhances objective authentic feelings.

To fully understand constructive authenticity, firstly, it should be based on the perspective of Constructivists. They argue that tourists seek authenticity, but what they seek is not objective authenticity but symbolic authenticity constructed by society (Wang 1999). This view argues that tourism objects are considered authentic not because they are originals or realities but because they are used as symbols of authenticity, or they are social constructions. This view sees reality as a social construct based on socially accepted norms and ideologies (Chronis and Hampton 2008). Thus, constructive authenticity is not necessarily related to reality (Wang 1999), but maybe the result of stakeholders' shared interpretation and construction. In sum, constructive authenticity does not emphasize the originality of the tourist object. Moreover, authenticity and inauthenticity are no longer dichotomous (Belhassen and Caton 2006). So, constructive authenticity varies depending on the perspective from which different people stand. For example, the contents of VR tourism are projected by destination managers based on their understanding of authenticity of the place. It may differ from tourists' perceptions of authenticity. Thus, to fully understand the authentic feelings, it is necessary to consider the understanding of the authenticity of VR tourism by different stakeholders.

Existential authenticity is another important aspect that is irrelevant to the objects (Nguyen and Cheung 2016; Reisinger and Steiner 2006). Existential authenticity is visible in collections of tourists' objects, destination sites, and commercialization in tourism industries. Therefore, existential authenticity constantly introduced new variables to affect the tourists' loyalty, consumption, behavior, etc. (Fu et al. 2018). More so than object-authenticity, existential authenticity was defined as 'subjective emotions, thoughts, bodily feelings, 
and experience, which means people mainly achieved a sense of authenticity through subjective emotion derived from internal activities' (Feiner et al. 1997; Yi et al. 2017). Wang (1999) classifies existential authenticity into intrapersonal and interpersonal authenticity. Kim and Jamal's (2007) research further measured the means of achieving a sense of intrapersonal and interpersonal authenticity through enhanced bodily feelings and expressing and developing intersubjective relationships with others.

Intrapersonal authenticity was defined as 'a sense of truth with tourists' selves, including their self-identity, self-satisfaction, and self-realization, making their bodily experiences feel more authentic and relaxed' (Xu et al. 2014). In tourism experiences, sensory stimuli such as sound, tactility, and vision meet the tourists' requirements for self-actualization and self-realization (Reisinger and Steiner 2006). Some studies evaluated intrapersonal authenticity through the lens of psychology and sociology; the perception of intrapersonal authenticity can make tourism experiences more real and vivid through means such as solo food, spa, and sports experiences (Kim et al. 2016; Lane and Waitt 2001). In VR tourism, contact with the site through VR technology allows visitors to participate in this adventure and explore the unknown themselves. These processes can enrich the content and increase the authenticity of the tour. Intrapersonal authenticity also includes an authentic sense of self-searching, adventure, exploration, and excitement that enables visitors to experience games where only one person goes on a journey to find the unknown and gain knowledge (Fu 2019). In other words, if tourism can satisfy tourists' perceptions by including aspects of exploration, excitement, and the unknown in the design of promotional videos or tourism equipment, it will attract tourists who are interested in these aspects to experience the journey. At the same time, interpersonal authenticity will be increased by advanced technologies such as VR products. In this regard, VR products can provide a realistic, simulated, unknown, and excellent journey, including live and interactive virtual environments to meet visitors' desire for intrapersonal authenticity.

Unlike intrapersonal authenticity, interpersonal authenticity focuses more on connection, not only with oneself but also with one's relatives, friends, and other people; interpersonal authenticity is more engrossing and vivid through interacting and working together with partners (Luo et al. 2008; McIntosh and Prentice 1999). Research has argued that in tourism experiences, the interaction and experience with the destination site are somehow more meaningful and engaging than the site's authenticity (Kim et al. 2016). This means that the sense of pleasure and satisfaction becomes more real and fulfilling when moving with the tourist's family, friends, or even strangers in the destination image. Interpersonal authenticity includes social and team interactions, and tourism experiences can provide the place, group, and scenery to attract people who want to reunite with relatives and friends. These people want to experience the colorful nature with their boyfriends or girlfriends. This sense of self-actualization is not limited to only themselves but also extends to their teams. In this regard, interpersonal interactions are a fundamental component of understanding interpersonal authenticity changes (Kim and Jamal 2007). 


\subsubsection{The authenticity in the postmodern approach}

To truly understand the authenticity from the postmodernist approach, this study first needs to outline what postmodernism is. Postmodernism has its origins in different fields such as art, architecture, film, tourism, especially the post-World War II tourism industry. It is a new cultural paradigm and social consciousness (Yi et al. 2018). Postmodernism was defined as 'a critique of modernity, which no longer takes absolute authenticity and modernization as universal' (D'Urso et al. 2016). It was characterized by uncertainty, diversity, and non-centrality, holding a "best of both worlds" rather than an "either/or" compromised view (Wang et al. 2015). This lack of authority, conclusiveness, and unity prevent postmodernism from simply being seen as a single, unified, and complete school of thought (Wang 1999).

In contrast to the modern tourist, the postmodern tourist can be described as someone who enjoys a variety of experiences. Their values are different from, or even opposite to, those of modern tourists, who seek authentic tourist attractions while still having to embrace the hyper-real (Yi et al. 2018). The diversity of their travel motivations and experiences has exceeded the explanatory power of traditional authenticity theory (Kim et al. 2018). For them, non-authenticity is no longer an issue because it usually provides a better and more exciting travel experience. Therefore, whether things are authentic or inauthentic has become irrelevant, and understanding postmodern authenticity should be assessed through multiple and incoherent lenses.

\subsection{Authenticity in VR experience}

With the advancement of ICT, tourists choose the destination based on the ICT platform more, and VR provides a new tourism experience method (Buhalis and Law 2008). VR connects the degrees of scenery restorations and authenticity of the natural landscape. Current research suggests that the application of VR in the tourism sector affects the travel experience in these three main ways (Guttentag 2010). Visualization means neither mobile-based nor computer-based VR products provide the 3D model, images, and other visual environment components to restore tourism objects, making tourists involved in the 'real-world' in tourism. From this perspective, object authenticity (objective and constructive) is related to the VR. Immersion and interaction in VR mean that physical sensations and phenomena created through VR technology can enrich the tourist's internal and external senses with emotions (Guttentag 2010). Through interacting with VR, they, friends, and relatives can make the authentic feelings stronger. The understanding of VR features is similar to existential reality, where talking, connecting, or interacting with relatives, friends, or even strangers in a specific activity can enhance the authenticity when using virtual reality in tourism.

From a postmodern perspective, people who are under much pressure or want to release negative emotions will choose VR as the platform to relax and search for liberation (Benckendorff et al. 2019). VR allows them to perceive the vivid, visual, and colorful world through 3D models and sound conducting to create new games, 
interactions, amusement, etc. (Nayyar et al. 2018). Through the design of interaction design and 'real' sensory design it affects the tourists' psychological performance. However, tourists may not focus on the experience or whether the object is authentic or inauthentic. The interaction is only to make them relax or escape pressure using the VR platform. Adding to the function of interaction and 'real' sensory design will connect the tourist existential authenticity based on the definition from Wang's (1999) research. To determine whether the presentation is authentic or inauthentic is not essential for them because their first aim is to relax and release pressure. Thus, from this perspective, tourists may consider VR experience based on postmodern perspective preferable to the alternative.

\section{Research method}

\subsection{The considerations of the research setting}

VR tourism is a relatively new form of tourism. The current studies of VR tourism are mainly from conceptual and qualitative perspectives, especially the few studies focused on authenticity issues of VR tourism. Therefore, the qualitative approach is adopted in this research.

Due to the impact of the Covid-19 pandemic, this study was conducted online. The research procedure follows the suggestions of internet-mediated research (IMR), such as follow the rules of 'netiquette,' send research questions and adverbs of purposes to relevant social media and discussion groups, and recruit nonprobability volunteer samples to achieve quality and valid data (Stephenson and Crete 2010). The obtrusive method of Computer-assisted video interviewing (CAVI) was applied for IMR designs data collection. The true volunteer' samples were invited to the interview. To obtain rich, detailed, reflective, and high-quality data, synchronous technologies, such as Instant Messaging and Chat software, were used, and the rapport-building was carefully designed (Jowett et al. 2011). The synchronous method is the simultaneous interview in which the interviewer and the interviewee interact remotely but interact in real-time (Hewson 2017).

While the study's main purpose is to explore the perceptions of authenticity of VR tourism, the samples should have experienced the same place or activities both offline and VR tourism before they participated in the interview. So the respondents should at least have had one of the VR experiences. Furthermore, to better understand the VR tourism products, the authors deeply experienced various types of VR tourism products in the current market, including natural destination, cultural tourism, museum, and programmed activities, such as underwater adventure, roller coaster, ski, and mountain-climbing.

\subsection{Sampling and data collection}

The qualified samples include both VR experts currently or formerly working in VR corporations and tourists who had VR tourism product experience. Based on the 
aforementioned research setting, when looking for potential VR tourism interviewees, we first posted the research questions on the social media of Zhihu and Xiaohongshu. When we received the responses from potential participants, we further approached them, introduced ourselves and the research purposes, and then asked them whether they were willing to participate in our online interview that would be recorded. After receiving their promises on the agreement, we added WeChat, a popular chat software in China, as an online interview platform.

Zhihu is a Chinese Q\&A site similar to Quora, which was launched in January 2011. Its slogan is "Share your knowledge, experience, and ideas with the world." On Zhihu, questions are created, answered, edited, and organized by users. As of May 2018, Zhihu had over 160 million registered users, an increase of $95.12 \%$ year-on-year. Most Zhihu users have higher incomes and more substantial purchasing power (Deng et al. 2020). Many well-known companies and startups operate accounts on Zhihu, which provides opportunities for people who want to find specialized fields and companies. Xiaohongshu has over 300 million registered users, with $70 \%$ of the users born after the 1990s. The number of monthly active users is over 85 million (Pemarathna 2019). The app allows users and well-known personnel to post and share product reviews, travel blogs, and lifestyle stories via short videos and photos in Mainland China. Although the age groups in these two social media are young, they are the major users of VR tourism products and one of the main segments of the tourism market.

The data was collected from June to July 2020. The in-depth semi-structured interview was applied to help researchers achieve a deep understanding of the topic and opinions, emotions, and motivations (Barriball and While 1994). The semistructured questions include (1) To what degree do you concern authenticity issues when experiencing VR tourism? (2) How would you describe the perceived authenticity in a VR tourism environment? (Probe question: are there criteria or references that help you demonstrate the authenticity of your perception?) To acquire and extract more Information and explore potential valuable data from respondents, we prepared the probes questions based on interviewees' responses. The leading questions were avoided during the interview, refrained from interrupting the interview, and fully listening to respondents' answers (Granot and Greene 2015).

It is essential that the respondents agreed on a term that means 'authenticity' so that they all have the common understanding of what the word implies. The meaning of "authenticity" is translated as "true to life" in Chinese. To ensure that the word "authenticity" was understood by all the interviewees, we translated the word "authenticity" back-to-back, which was also endorsed by the experts in our university. The interviewees' answers will still depend on their individual assumption of the authenticity of the presentation, $70 \%$ of the respondents found the presentation authentic.

The in-depth interviews about the perception of authenticity had an average time of about $45 \mathrm{~min}$. The interviews were digitally recorded and transcribed verbatim. When using the WeChat interview, the professional recording software was used to record the voice data obtained via WeChat. Later, this voice data was translated into text utilizing Xunjie software. Xunjie was founded in 1998 and is a member of the China Packaging Technology Association. During the interviews, the interviewer 
remained neutral and understood the results of the interviewees. One interviewee's opinion was compared with later or former interviewees' answers, which can help us understand the concepts more comprehensively. Meanwhile, in this process, research confirms the answers based on respondents' answers during the interview. Finally, the theoretical saturation was reached, and 28 interviews were obtained for the final data analysis.

\subsection{Data analysis}

In this study, data analysis followed the procedures of the thematic analysis. This method is suitable for the research purpose of interpretating tourists' perceptions of authenticity issues in VR tourism, especially applying both inductive and deductive methods to data analysis (Alhojailan 2012). As suggested by the previous researchers, when analyzing the data, the researchers must immerse into the data, and then by inductive approach develop the code list, testing the reliability of the code, and constructing initial themes; after the rectification of themes, adopting the deductive method to finalize the themes (Fereday and Muir-Cochrane 2006; Vaismoradi et al. 2016).

Guided by the procedures of the thematic analysis, the researchers analyzed the results, based on the data per se, with an open mind and focus on the issues mentioned by the participants. A total of 412 codes were obtained initially, and then further collated the data by reducing the repeated codes, 122 codes were extracted finally. The Nivio12 plus, a qualitative data analysis software, was used by the authors organize the interview data and manage the codification process. In the process of theme generation, the authors applied the inductive method to summarize the codes into 15 categories, and further emerged as six sub-themes. Finally, by applying the deductive method, the three themes were identified (refer to Fig. 1). This is the flexibility of thematic analysis that researchers are allowed to apply multiple ways to verify themes (Fereday and Muir-Cochrane 2006; Vaismoradi et al. 2016). Figures 2 and 3 are the examples of data analysis. To reach the validity, the authors independently coded the interview data based on their own understanding, and then they discussed the cording list together to reach a consensus. Finally, the authors discussed and revised the results with the experts from the same university.

\section{Findings and discussion}

\subsection{Respondents information}

All the respondents are active travelers, they prefer to explore unique places with outstanding landscapes and cultures. Before the interview, they all had VR tourism product experiences, including museum VR experience, destination VR produced by Holographic photography, and computer-generated 3D environment. There are seven experts who working in VR technology companies amongst the participants and twenty-one tourists who had VR tourism product experiences. The experts 


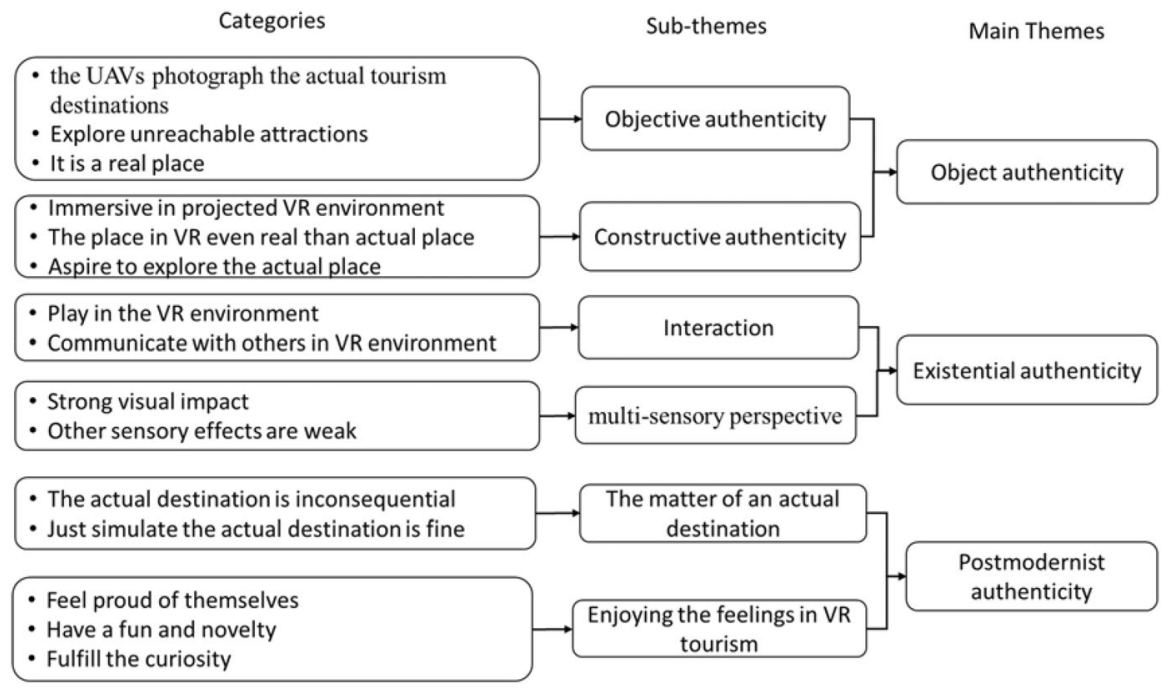

Fig. 1 The themes of perceived authenticity in VR tourism

responded to the interview questions from both designer and tourist perspectives, while the tourists shared their personal VR experiences only. For example, one of the experts shared that their company made a VR attraction for the client based on the Google Earth, they thought the VR truly represent the place, however, their client said: yes, it is real, but it feels lacking in authenticity. Finally, they found the reason. While the VR content truly represents the place, their client lives in the place and they can tell some details, and the width of the river and the thickness of the trees are the main reasons why the client feels that the presentation is unreal. Apart from the experts providing more detailed knowledge of VR design, there are no differences in authenticity issues, hence, the data was analyzed together.

Their background Information refers to Table 1 . About $50 \%$ of participants are male, and $50 \%$ are female. Over $96 \%$ of the respondents have college degree. The age range is between 18 and 50 years old. The participants between the age 18-25 represent the majority, suggesting that young people are major tourists to the VR tourism market. The present study coded the participants into $\operatorname{EP}(X)$ and $\operatorname{TP}(X)$. $\mathrm{EP}(\mathrm{X})$ represents expert participants; for example, the first expert participant will be labeled EP1. In the same way, TP(X) refers to the tourist participants, with TP1 indicating the first tourist respondent.

\subsection{Object authenticity}

Object authenticity can be further divided into objectivist and constructivist approaches (Wang 1999). Objective authenticity is determined by testing or evaluating it according to specific parameters relevant to an object's pure, original, and genuine version. Constructivist authenticity refers to the authenticity projected by tourists or tourism producers in terms of their imagery, aspirations, desires, values, 


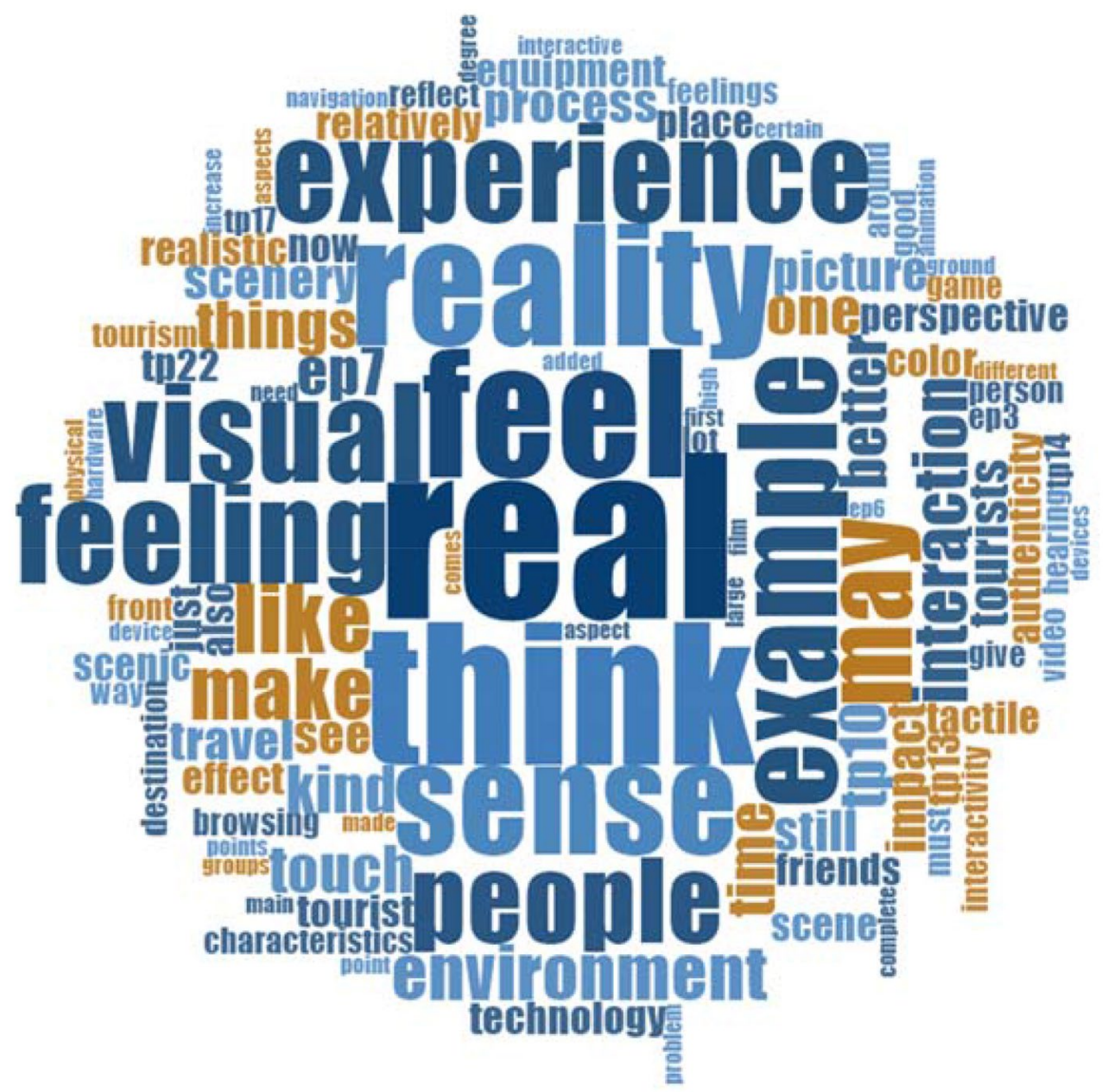

Fig. 2 An example of data analysis

forces, etc. (Lin and Liu 2018; Wang 1999). In the current VR market, one way to produce VR tourism products is to apply holographic photography. In this way, the producers use the UAVs (unmanned aerial vehicles) photograph the actual tourism destinations. From this perspective, it is a genuine version of a place. When the tourists experience this type of VR tourism, they feel fully immersed and have authentic feelings. Without virtual reality technology, they would not be able to explore many unreachable attractions and have a bir's eye view of the entire picture of this place.

TP23: Because one of the technical features from VR will allow you to immerse yourself in it. For example, I have been to a spot to play called the 'leap Jiangsu', I do not know if you have the feelings, that is the kind of immersive feeling. From the hand touch on it, you will feel that it will have let you have a kind of 'immersive' feeling (of authenticity).

TP15: I prefer VR because it is a more authentic way to immerse yourself in the world than other kinds of tourism videos. It will give the traveler a sense 


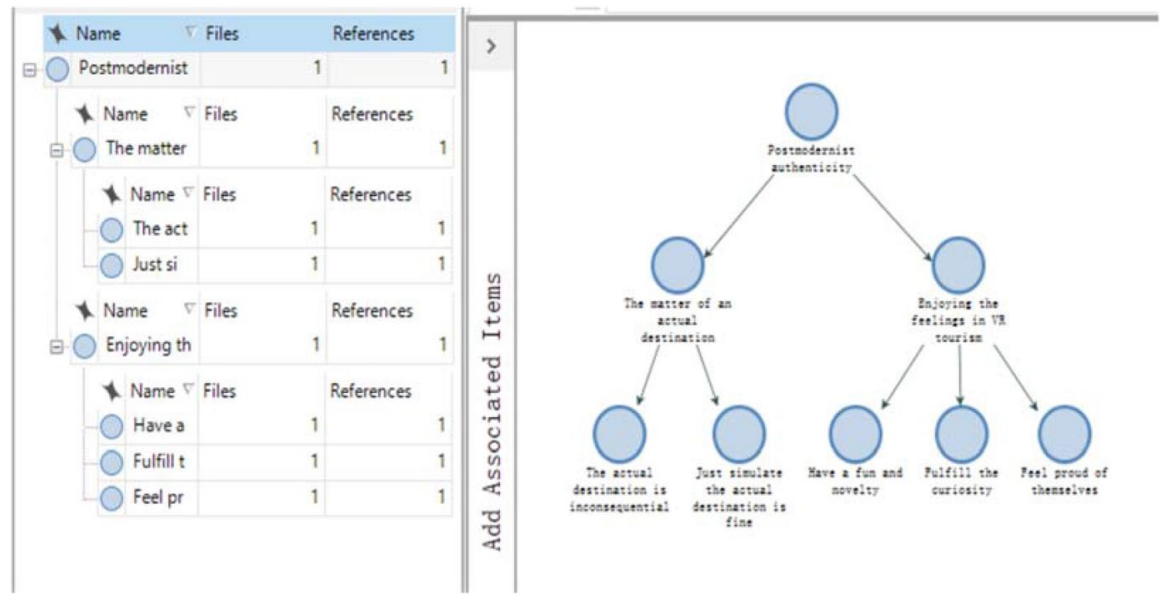

Fig. 3 An example of data analysis

of authenticity, and (the feelings) will be very strong. The whole feeling of the atmosphere, space, and distance will be there than a more hierarchical sense.

However, the length of VR tourism is limited to about ten minutes because people will begin to feel dizzy if the film is too long. It is impossible to show the whole place through VR tourism in such a limited time. In this sense, the destination managers and producers have to reconstruct meaningful and valuable places in VR tourism. From the tourist'" perspective, they do understand that it is a virtual reality environment. They do not care about the "real" but search for clues that they believe to be real based on the knowledge gained through various Information. As they mentioned, virtual reality products are shot in the best season of the year. However, they may miss the best season when they visit the place, so they cannot experience the best scenery.

EP7: That kind of pure virtual VR, one is to shoot in the real world. I won't say what I shot in the real world. If it is purely virtual, it also depends on its degree of reduction. The closer we are to reality, the stronger our sense of experience is.

TP16: The main thing is whether it can reflect a real-time change. In addition to real-time, a relatively small detail determines authenticity. However, if there is no real-time detail, it is somewhat real on a large scale.

People are looking for object authenticity in VR products mainly to help choose their favorite tourism destination. Based on this consideration, they expect VR tourism products to be as close as possible to actual tourism destinations.

TP10: For example, nowadays, when you buy goods, just like when we shop at Taobao, there is a big difference between the pictures you see and the goods you buyback, its quality and use are very different. I use VR to choose a travel destination. For example, it shows me the destination, and when I really visit 
the destination, it is there is a difference, it is really as beautiful or so attractive, or I am very interested in the point, whether it contains just you talk about the sense of authenticity.

\subsection{Existential authenticity}

Existential authenticity emphasizes subjective emotions, thoughts, physical feelings and experience (Yi et al. 2017), which means that people mainly obtain subjective emotions from internal activities. It can be achieved through experiencing activities such as interacting with families, friends, and themselves. Intrapersonal authenticity and interpersonal authenticity are two dimensions of existential authenticity (Wang 1999). Based on the interview data, both experts and tourists highlight the existential authenticity aspect. They discussed the perception of authenticity mainly from an interactive and multi-sensory perspective.

Interaction is a key concept in the tourism experience that affects the choice of a tourist destination ( $\mathrm{Liu}$ et al. 2020). Adding interactive functions to travel can enhance the connection between tourists and themselves and improve the friendship between relatives and friends (Prentice et al. 1994). Most tourists see interaction as a major feature of the travel experience. From the perspective of perceived authenticity, interpersonal authenticity focuses on their friends and relatives ( $\mathrm{Fu}$ et al. 2018; $\mathrm{Xu}$ et al. 2014). This explains why respondents believe that the sense of authenticity is greatly enhanced by increasing interaction in VR tourism. As they mentioned, tourists feel very lonely when experiencing current VR products, so it is difficult to feel a sense of reality. One of the respondents (EP7) said that if a cartoon character or artificial intelligence character guides you to explore the destination in the VR environment, they can connect you to the surrounding environment and make you feel natural. Although current VR products lack interaction with others and the surrounding environment, they still enjoy the VR experience and have authentic feelings.

TP25: I think interaction can be added to it (VR) and then affect your sense of reality. For places with local characteristics, adding interaction with locals to $V R$ experience will enhance authentic feelings.

EP1: One reason interactivity is also critical is that the tourism industry itself is relatively unique. Generally, most people travel in groups, that is, they go out with family and friends.

EP5: VR tells you that it can only watch and walk inside, but you can't play some games, such as bowling and roller coasters. Yes, I think all of these have to be added. And then there are some characters to talk to you about. Restore this interactivity to the game, as well as some scenes.

TP20: There is another (VR experience), I do' 't know if you have experienced it? (Some places when you are in the VR experience), as well as outside there will be some venues and some staff will give you some environmental atmosphere, This atmosphere coupled with VR promotion, (based on VR technology can create an effect).I think it matches quite well. There are also some outside 
environments, the integration of the two, will also make you feel more authentic.

The respondents also stated that multi-sensorial stimulation could enhance the perception of authenticity when using VR products. In current VR tourism products, they can only experience senses of visual and auditory. Though these two senses bring authentic feelings to the VR tourism experience, they also look forward to smell, taste and touch. However, there are more interactive designs and powerful visual effects in some VR games; hence, experiencing VR games is more popular than VR tourism products.

EP7: This sound of traffic, which these details can be handled very well, and my auditory effect is excellent. Of course, it will also be very shocking and make me feel more real.

TP13: The visual and technical aspects will make you feel that it is more real and then truly reflect your tourist destination.

EP3: This is called visual impact, which is very strong, even stronger than VR movies. So, when we do some interactive games, when there are shooters, we will purposely put the enemy's bullets into the experimenter's vision on the side of our lens. In this way, it feels like the bullets are turning around really or realistically.

This finding is consistent with previous studies, such as (Mura and Lovelock 2009) study, which showed that the perception of authenticity is affected by all different body sensations. When tourists participate in activities, their sensory perception will be affected. Thus, it can be understood that authenticity can change a tourism experience (Chhabra 2010). Mura et al. (2017) also found that VR tourism is very close to real products, but people prefer to experience the natural destination environment through human sensory organs. However, under current technical conditions, it is impossible to experience a sense of "touch", "smell" and "taste" in VR experiences.

Kim and Hall (2019) proposed that VR products can stimulate tourists' motivation and affect their physical feelings, which means that VR is meaningful and beneficial for tourists to relax. This explains why based on the sensory system, the feelings of authenticity of tourists in the VR environment can be greatly enhanced. Furthermore, respondents believe that when touching these VR devices, the effectiveness of information technology will make them feel both natural and unbelievable. The previous research can prove that touching objects can improve the authentic perception of tourists in the travel experience (Kontogeorgopoulos 2017).

\subsection{Postmodernist authenticity}

Beauty is in the eye of the beholder. This phrase best illustrates the meaning of postmodernist authenticity. True or false is not the main issue of authenticity in postmodernism, but by destroying the boundary between the copy and the original or between the symbol and reality to deconstruct the concept of authenticity (Wang 1999). The postmodernist tourism perspective emphasizes experience and emotions 
because postmodernist tourists seek enjoyment and have fun rather than authenticity (Shehade and Stylianou-Lambert 2020).

In addition to holographic photography, computer-generated 3D environments are the main way to produce VR tourism products, such as climbing Mount Everest, swimming in the underwater world, skiing, and roller coasters. The respondents said they do not really care whether it is the real Mount Everest or the real underwater world. In reality, they cannot really climb Mount Everest or interact with marine life underwater and play together. So, they enjoyed this feeling so much in a VR environment. When they climbed to the summit of Mount Everest, they felt that they were actually on Mount Everest and were proud of themselves. They fully understand that this is not true, but they still feel it is authentic.

TP11: I play (VR) is a jungle adventure (type). Psychologically, you may feel that (the jungle experience) will encounter some more dangerous items. However, (I know it myself) is in the virtual environment of VR, there may be a more authentic feeling than the real place, the heart is slightly less afraid. Because (I) know that this is a virtual scene, but also can bring you into the scene inside.

TP15: Compared to other ways of traveling, I think these features (can help me get to) places that I may not be able to get to at the moment. (Through VR experience), I's not dangerous, but I's exciting. It makes you want to play again after you have played once. (For example, VR experience) is to leap over the horizon, is (let you feel) fly over various places of interest. (Because) you may not currently be able to reach these places, but through (VR) technology allows you to feel (can go to experience). (For example) personally experience these places of interest as well as the stars and the sea. And then. These landscapes are also very beautiful and impressive. I's the kind of thing that can only be presented through VR technology, but not in any other way.

According to the interview data, people experience VR tourism products mainly for fun and novelty. The objective authenticity of VR products is not a critical issue when they experience the products. However, postmodern authenticity plays a crucial role in VR tourism products because the current technological development can even create a VR environment that is more realistic than the real destinations, and tourists enjoy the tourism destinations in the VR environment more than the reality. The case of Walt Disney World (WDW) can explain this phenomenon well. When people visit WDW, tourists are surrounded by created stories and imagined atmosphere and enjoy it (Boje 1995).

TP23: The nature (of the tour experience) may not be the same, but it may be a little more shocking with VR, which may be a little more exciting than your actual browsing process.

\subsection{The framework of authenticity of VR tourism}

Through deep immersion into the interview data and thematic analysis, a framework is emerged (see Fig. 4). The foundation of the framework relates to tourists' 
authenticity orientation and production method of VR contents, which are computer-generated 3D environment (VE) and holographic photography. When tourists' intention is to search for a certain destination through VR tourism products, they are more likely oriented toward a search for the authentic. Given that, objective authenticity plays an important role, and holographic photography VR is preferred as tourists perceive this type of VR products to be "real" places. In addition, the constructive authenticity is also accepted as the destination planners attempt to promote the uniqueness of attractions of the place, through the projected authenticity, the tourists can explore more unreachable attractions for various reasons, such as seasonal difference and timely or physical energy issues.

If tourists choose VR products for fun and some activities that are impossible for them to experience in real life, they are inclined toward an inauthentic orientation. Consequently, postmodernist authenticity plays a key role, and computer-generated $3 \mathrm{D}$ environment VR products are required. In this context, tourists mainly expect to fulfill their self-esteem and desire for exhilarating and unique experiences. In both object and hyperreality, interaction within the VR tourism and requirements of multiple sensory experiences were proposed by the participants, especially in VR products that were produced through VE method, which relate to hyperreality. In VR tourism context, existential authenticity intersects with other two types of authenticity. It is easy to understand that products designed in VE method are about activities, such as underwater adventure and skiing. However, as defined by Wang (1999), existential authenticity is unrelated to object authenticity. In this study, it can be interpreted through postmodernist perspective that although object authenticity relates to original places, but it is presented in VR environment, as the saying

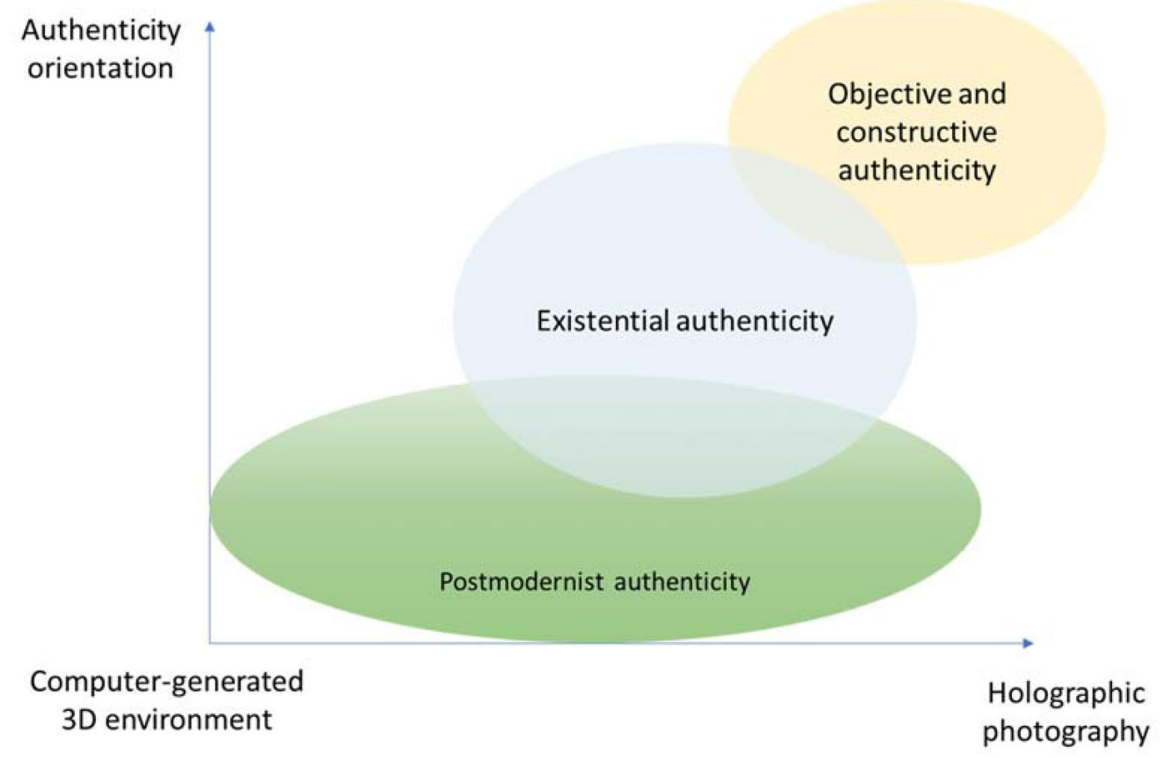

Fig. 4 The framework of authenticity in VR tourism 


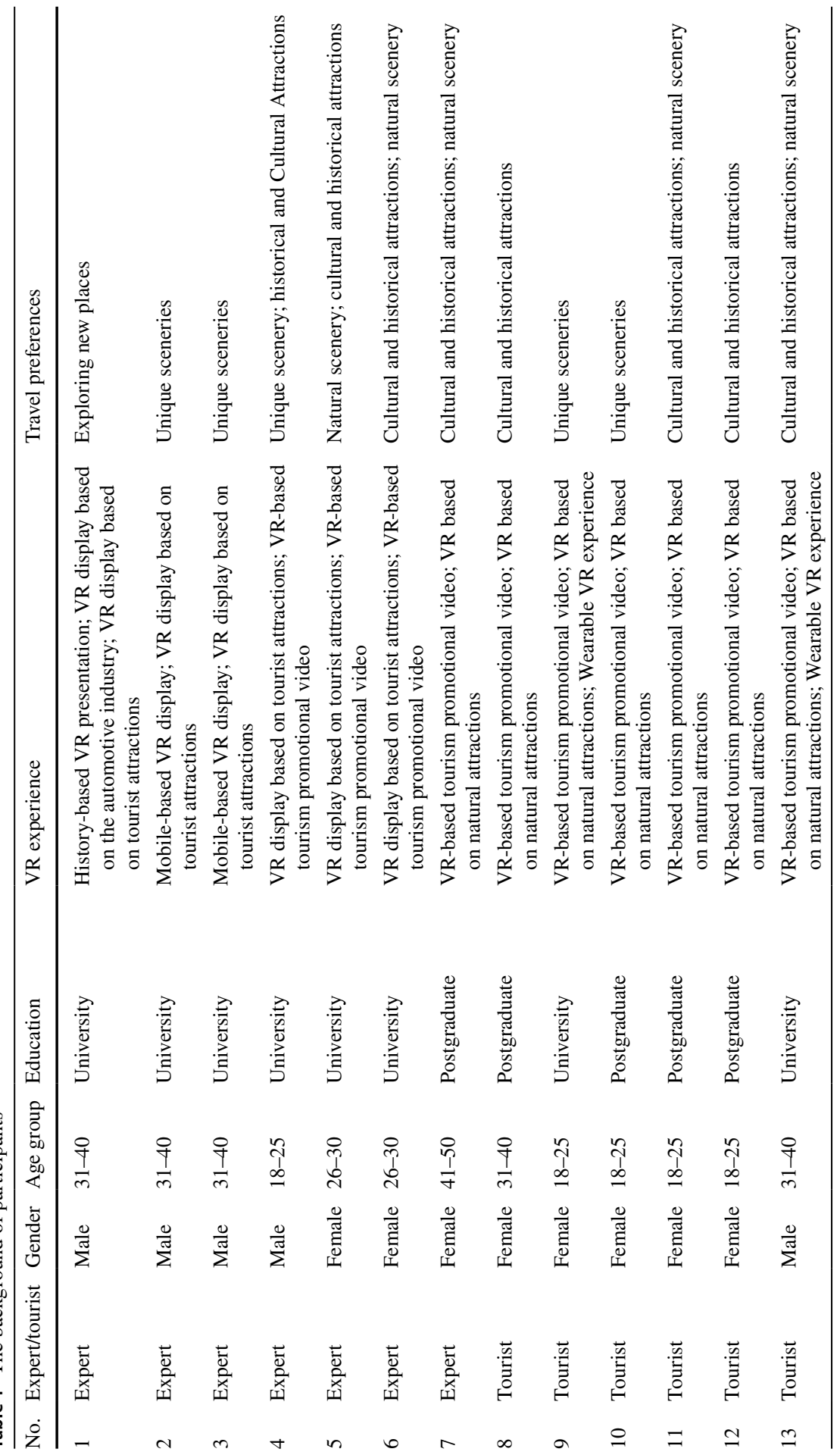




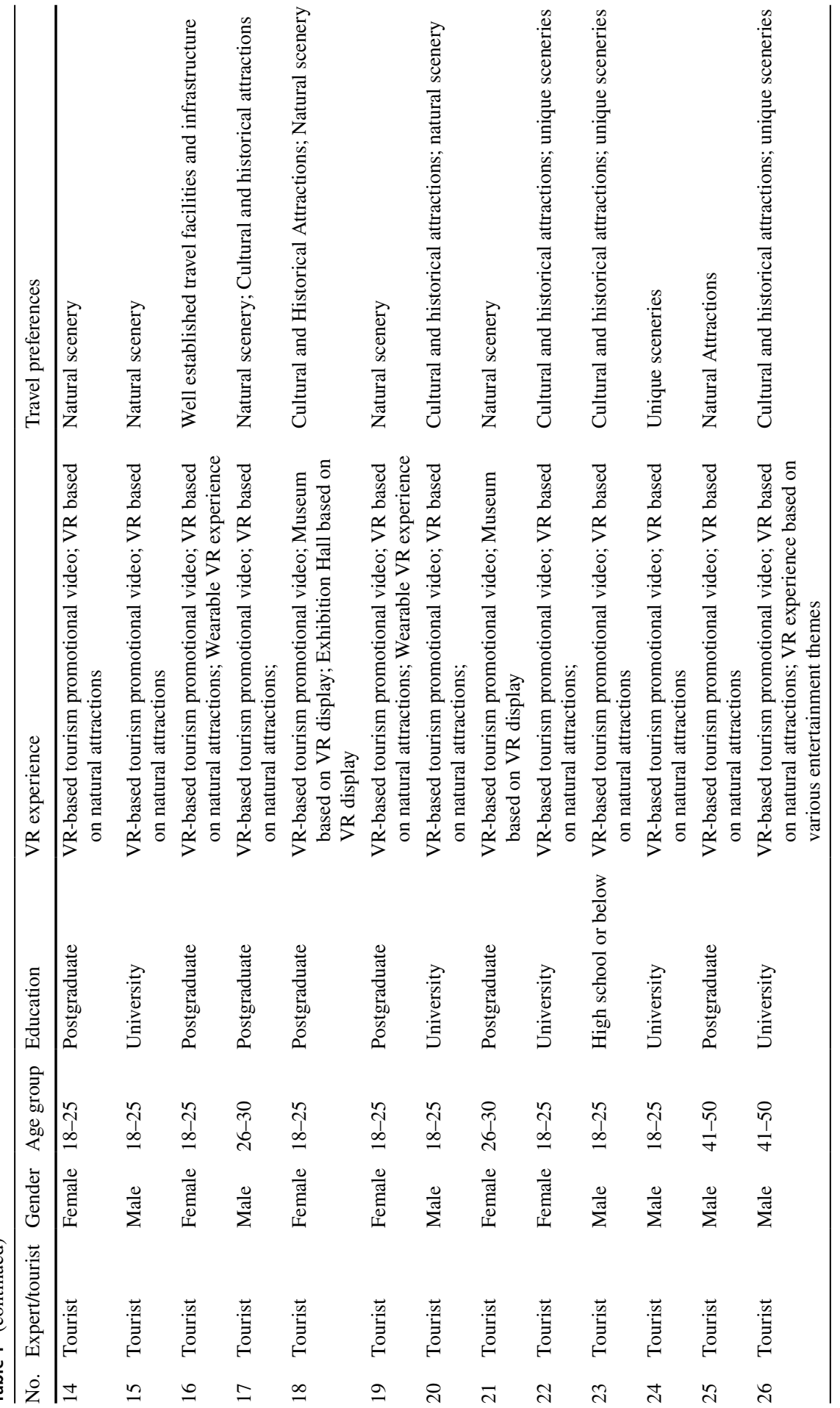




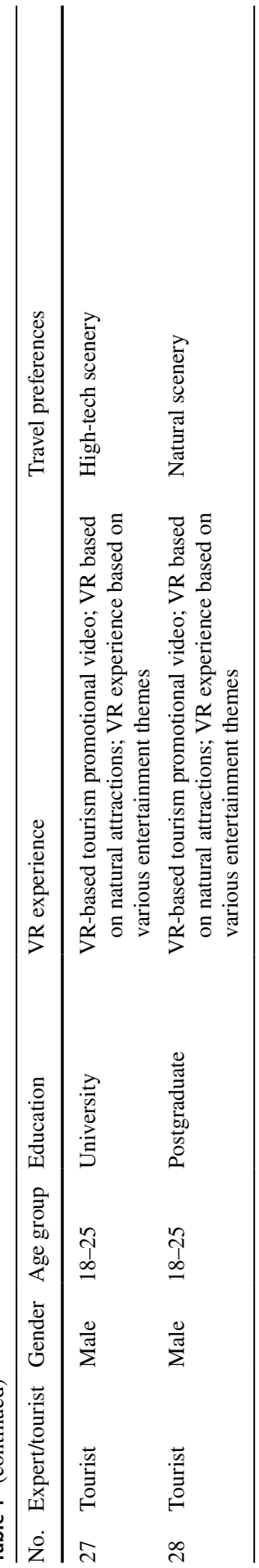

글 Springer 
in 《A Dream of Red Mansions》 “Truth becomes fiction when the fiction's true; Real becomes not-real where the unreal's real" (Tsao and Kao 1994). It is essential to involve the tourists into the scenery in VR tourism context that is produced by holography, by doing so, interaction and multiple sensory experience are vital. The proposed framework is in line with the findings of a recent publication. Stepchenkova and Belyaeva (2021) who argue that in recreated tourism destination setting, existential authenticity impact on revisit intention and it is affected by authenticity orientation. Postmodernists are not affected by the tourism setting, they appreciate sites even outside their expectations.

\section{Conclusion and Limitations}

The aim of this study is to explore the perceived authenticity in VR tourism context from a postmodernist approach. The contents of VR tourism are computer-generated $3 \mathrm{D}$ environment or projected places. Thus it could never be authentic places, however, authenticity is a key factor influencing tourist motivation, information search behavior, destination imagery and travel intention (Ramkissoon and Uysal 2011). Thus, it is essential to explore the perceptions of authenticity of a new tourism platform, VR tourism. Based on the interview data, by applying the thematic analysis, three themes of object, existential and postmodernist authenticity are extracted. The six sub-themes of each main themes are also illustrated. Finally, the framework of authenticity in VR tourism is developed and discussed.

In this study, the research mainly focuses on the application of authenticity theory in VR tourism experience. Authenticity plays an essential role in the tourist experience, affecting various behaviors and intentions, such as tourist perceptions and behavior. Based on this theoretical background, this paper finds that authenticity as a crucial factor based on VR platforms can influence tourist future travel intention and alter the perceptions of actual tourism destinations. The findings also fill the gap in authenticity for ICT aspects and provides references for future research. The current study further enriches authenticity research content and the literature review on perceived authenticity from postmodernist approach. The framework illustrates the relationship between authenticity orientation and tourism destination settings in VR tourism context, which refer to the production methods of VR contents.

Nowadays tourism destination managers are in favor of virtual reality technology as a new marketing and entertainment method to attract tourists. Among them are building VR theme parks, VR restaurants, VR games, VR travel documentaries and other factors to attract tourists, especially during Covid-19 (Kwok and Koh 2021). Tourists are gradually starting to try this ICT-based tourism experience. It is possible to do it without leaving home through an online experience, which saves time and effort. However, it inevitably leads to overcapacity and homogenized products in the current VR tourism market, which will undoubtedly put its operations at risk. Therefore, the researchers would like to provide some suggestions based on the findings. First, it is doable to produce a VR experience on site, but attention must be paid to the contents. Based upon the findings, the contents of VR tourism are produced either by Holographic live shooting (objective authenticity) or computer-generated 
VR (constructive authenticity). It is better to promote the best seasonal specials and unreachable attractions, rather than an edited version of an entire place, like the VR of flying over the West Lake. Tourists believe that the tourist destinations photographed with holograms are real, therefore, they expect to experience VR tourism to offset for missed sceneries or attractions due to various reasons. Second, communicating and playing with others are so important and emphasized by the participants, especially senses of taste, smell, and touch. These feedbacks are linked with existential authenticity, and maybe this is a big challenge for producers that is possible to solve based on existing technology. For example, there are some advanced wearable devices that can help tourists achieve existential authenticity along with VR glasses. This can also be achieved through computer-generated VR design. Finally, for tourists who are postmodernist authenticity driven, they experience the products of VE are more likely ignore the actual destination but focus on entertainment and fun. They also expect to fulfill extraordinary experiences that are impossible for them to achieve in real life. The tourists' expectations will be satisfied if the producers consider these issues when designing the VR products.

The current study has some limitations. The first limitation refers to the background of the participants. In this study, the samples are mainland Chinese, aged between 18 and 30 years, and their perceptions of authenticity might be different from those from other cultural backgrounds or age groups. In a future study, it is better to recruit samples of cross-cultural background and expand the scope of age groups. In addition, we did not focus on a specific VR tourism product in this study, such as museum, heritage tourism, scenery, and a product of VE. This may affect the specific findings for each type of tourism attraction; however, it gave us a whole picture of perceived authenticity in VR tourism. Moreover, we did not clearly distinguish the perceptions of authenticity of a destination before and after the VR experience. If we can obtain these two sets of data, it will help us investigate whether the VR experience has changed the authenticity perception of the actual destination experience.

\section{References}

Alhojailan MI (2012) Thematic analysis a critical review of its process and evaluation. West East J Soc Sci 1(1):39-47

Barriball KL, While A (1994) Collecting data using a semi-structured interview a discussion paper. J Adv Nurs 19:328-335

Bec A, Moyle B, Timms K, Schaffer V, Skavronskaya L, Little C (2019) Management of immersive heritage tourism experiences: a conceptual model. Tour Manage 72:117-120. https://doi.org/10.1016/j. tourman.2018.10.033

Belhassen Y, Caton K (2006) Authenticity matters. Ann Tour Res 33(3):853-856. https://doi.org/10. 1016/j.annals.2006.03.009

Belhassen Y, Caton K, Stewart WP (2008) The search for authenticity in the pilgrim experience. Ann Tour Res 35(3):668-689. https://doi.org/10.1016/j.annals.2008.03.007

Benckendorff PJ, Xiang Z, Sheldon PJ (2019) Tourism Information Technology, 3rd Edition. CABI.

Boje DM (1995) Stories of the storytelling organization a postmodern analysis of disney as tamara-land. Acad Manag 38(4):997-1035 
Buhalis D, Law R (2008) Progress in information technology and tourism management: 20 years on and 10 years after the Internet-the state of eTourism research. Tour Manage 29(4):609-623. https://doi. org/10.1016/j.tourman.2008.01.005

Chhabra D (2010) Branding authenticity. Tour Anal 15(6):735-740. https://doi.org/10.3727/108354210X 12904412050134

Chhabra D, Healy R, Sills E (2003) Staged authenticity and heritage tourism. Ann Tour Res 30(3):702719. https://doi.org/10.1016/S0160-7383(03)00044-6

Chronis A, Hampton RD (2008) Consuming the authentic Gettysburg: how a tourist landscape becomes an authentic experience. J Consumer Behav Int Res Rev 7(2):111-126. https://doi.org/10.1002/cb. 241

Deng S, Jiang Y, Li H, Liu Y (2020) Who contributes what? Scrutinizing the activity data of 42 million Zhihu users via immersion scores. Inform Process Manag 57(5):102274. https://doi.org/10.1016/j. ipm.2020.102274

Dueholm J, Smed KM (2014) Heritage authenticities-a case study of authenticity perceptions at a Danish heritage site. J Herit Tour 9(4):285-298. https://doi.org/10.1080/1743873X.2014.905582

D’Urso P, Disegna M, Massari R, Osti L (2016) Fuzzy segmentation of postmodern tourists. Tour Manage 55:297-308. https://doi.org/10.1016/j.tourman.2016.03.018

Feiner S, MacIntyre B, Höllerer T, Webster A (1997) A touring machine: prototyping 3D mobile augmented reality systems for exploring the urban environment. Pers Technol 1(4):208-217. https://doi. org/10.1007/BF01682023

Fereday J, Muir-Cochrane E (2006) Demonstrating rigor using thematic analysis a hybrid approach of inductive and deductive coding and theme development. Int J Qual Methods 5(1):80-92

Fu X (2019) Existential authenticity and destination loyalty: Evidence from heritage tourists. J Destin Mark Manag 12:84-94. https://doi.org/10.1016/j.jdmm.2019.03.008

Fu Y, Liu X, Wang Y, Chao R-F (2018) How experiential consumption moderates the effects of souvenir authenticity on behavioral intention through perceived value. Tour Manage 69:356-367. https://doi. org/10.1016/j.tourman.2018.06.023

Granot E, Greene H (2015) A structural guide to interviewing as qualitative marketing research The three interview series model. In Marketing, Technology and Customer Commitment in the New Economy (pp. 77-81). Springer, Berlin

Guttentag DA (2010) Virtual reality: applications and implications for tourism. Tour Manage 31(5):637651. https://doi.org/10.1016/j.tourman.2009.07.003

Hewson C (2017) Research design and tools for online research. In: Ffiedlding NG, Lee RM, Blank G (eds) The Sage handbook of online research methods (Second Edition ed). SAGE Publications, pp $57-75$

Huang YC, Backman KF, Backman SJ, Chang LL (2016) Exploring the implications of virtual reality technology in tourism marketing: an integrated research framework. Int J Tour Res 18(2):116-128. https://doi.org/10.1002/jtr.2038

Izard SG, Juanes JA, García Peñalvo FJ, Estella JMG, Ledesma MJS, Ruisoto P (2018) Virtual reality as an educational and training tool for medicine. J Med Syst 42(3):50. https://doi.org/10.1007/ s10916-018-0900-2

Jowett A, Peel E, Shaw R (2011) Online Interviewing in psychology: reflections on the process. Qual Res Psychol 8(4):354-369. https://doi.org/10.1080/14780887.2010.500352

Jung TH, Tom Dieck MC (2017) Augmented reality, virtual reality and 3D printing for the co-creation of value for the visitor experience at cultural heritage places. J Place Manag Dev 10(2):140-151. https://doi.org/10.1108/JPMD-07-2016-0045

Kim MJ, Hall CM (2019) A hedonic motivation model in virtual reality tourism: comparing visitors and non-visitors. Int J Inf Manage 46:236-249. https://doi.org/10.1016/j.ijinfomgt.2018.11.016

Kim H, Jamal T (2007) Touristic quest for existential authenticity. Ann Tour Res 34(1):181-201. https:// doi.org/10.1016/j.annals.2006.07.009

Kim MJ, Lee C-K, Bonn M (2016) The effect of social capital and altruism on seniors' revisit intention to social network sites for tourism-related purposes. Tour Manage 53:96-107. https://doi.org/10. 1016/j.tourman.2015.09.007

Kim S, Park S, Santos CA, Shinew KJ (2018) (Re) negotiating authenticity through virtual travel: a case study of Law of the Jungle, a Korean reality travel program. J Travel Tour Mark 35(3):348-364. https://doi.org/10.1080/10548408.2017.1318735

Kontogeorgopoulos N (2017) Forays into the backstage: volunteer tourism and the pursuit of object authenticity. J Tour Cult Chang 15(5):455-475. https://doi.org/10.1080/14766825.2016.1184673 
Kwok AO, Koh SG (2021) COVID-19 and extended reality (XR). Curr Issue Tour 24(14):1935-1940

Lane R, Waitt G (2001) Authenticity in tourism and native title: place, time and spatial politics in the east Kimberley. Soc Cult Geogr 2(4):381-405. https://doi.org/10.1080/14649360120092607

Lau RW (2010) Revisiting authenticity: a social realist approach. Ann Tour Res 37(2):478-498. https:// doi.org/10.1016/j.annals.2009.11.002

Lin YC, Liu YC (2018) Deconstructing the internal structure of perceived authenticity for heritage tourism [Article]. J Sustain Tour 26(12):2134-2152. https://doi.org/10.1080/09669582.2018.1545022

Lin H, Zhang M, Gursoy D, Fu X (2019) Impact of tourist-to-tourist interaction on tourism experience: the mediating role of cohesion and intimacy. Ann Tour Res 76:153-167. https://doi.org/10.1016/j. annals.2019.03.009

Lin L-P (Lynn), Huang S-C (Lucy), Ho Y-C (2020) Could virtual reality effectively market slow travel in a heritage destination? Tour Manag 78: 104027. https://doi.org/10.1016/j.tourman.2019.104027

Liu Y, Hultman M, Eisingerich AB, Wei X (2020) How does brand loyalty interact with tourism destination? Exploring the effect of brand loyalty on place attachment. Ann Tour Res 81:102879. https:// doi.org/10.1016/j.annals.2020.102879

Lunchaprasith T, Macleod D (2018) Food tourism and the use of authenticity in Thailand. Tour Cult Commun 18(2):101-116. https://doi.org/10.3727/109830418X15230353469492

Luo R, Xiao S, Jiang Y, Jin H, Wang D, Liu M, Chen H, Fang L (2008) Porcine reproductive and respiratory syndrome virus (PRRSV) suppresses interferon- $\beta$ production by interfering with the RIG-I signaling pathway. Mol Immunol 45(10):2839-2846. https://doi.org/10.1016/j.molimm.2008.01.028

MacCannell D (1973) Staged authenticity: arrangements of social space in tourist settings. Am J Sociol 79(3):589-603. https://doi.org/10.1086/225585

McIntosh AJ, Prentice CR (1999) Affirming authenticity: consuming cultural heritage. Ann Tour Res 26(3):589-612. https://doi.org/10.1016/S0160-7383(99)00010-9

Mura P, Lovelock B (2009) A not so little Italy? Tourist and resident perceptions of authenticity in Leichhardt Sydney. Tour Cult Commun 9(1-2):29-48. https://doi.org/10.3727/109830409787556620

Mura P, Tavakoli R, Sharif SP (2017) 'Authentic but not too much': exploring perceptions of authenticity of virtual tourism. Inform Technol Tour 17(2):145-159. https://doi.org/10.1007/s40558-016-0059-y

Nayyar A, Mahapatra B, Le Nhuong D, Suseendran G (2018) Virtual reality (VR) and augmented reality (AR) technologies for tourism and hospitality industry. Int J Eng Technol 7(221):156

Nguyen THH, Cheung C (2016) Chinese heritage tourists to heritage sites: what are the effects of heritage motivation and perceived authenticity on satisfaction? Asia Pacific J Tour Res 21(11):11551168. https://doi.org/10.1080/10941665.2015.1125377

Papachristos NM, Vrellis I, Mikropoulos TA (2017) A comparison between oculus rift and a low-cost smartphone VR headset: immersive user experience and learning. In: 2017 IEEE 17th International Conference on Advanced Learning Technologies (ICALT), pp 477-481.

Pemarathna R (2019) Impact of xiaohongshu on its user based and society: a review.

Poux F, Valembois Q, Mattes C, Kobbelt L, Billen R (2020) Initial user-centered design of a virtual reality heritage system: applications for digital tourism. Remote Sens 12(16):2583. https://doi.org/10. 3390/rs12162583

Prentice RC, Witt SF, Wydenbach EG (1994) The endearment behaviour of tourists through their interaction with the host community. Tour Manage 15(2):117-125. https://doi.org/10.1016/0261-5177(94) 90005-1

Ramkissoon H, Uysal MS (2011) The effects of perceived authenticity, information search behaviour, motivation and destination imagery on cultural behavioural intentions of tourists. Curr Issue Tour 14(6):537-562. https://doi.org/10.1080/13683500.2010.493607

Reisinger Y, Steiner CJ (2006) Reconceptualizing object authenticity. Ann Tour Res 33(1):65-86. https:// doi.org/10.1016/j.annals.2005.04.003

Rickly-Boyd JM (2012) Authenticity and aura: a benjaminian approach to tourism. Ann Tour Res 39(1):269-289. https://doi.org/10.1016/j.annals.2011.05.003

Shehade M, Stylianou-Lambert T (2020) Revisiting authenticity in the age of the digital transformation of cultural tourism. In: Cultural and tourism innovation in the digital Era (pp. 3-16). Springer.

Simon SC, Greitemeyer T (2019) The impact of immersion on the perception of pornography: a virtual reality study. Comput Hum Behav 93:141-148. https://doi.org/10.1016/j.chb.2018.12.018

Steiner CJ, Reisinger Y (2006) Understanding existential authenticity. Ann Tour Res 33(2):299-318. https://doi.org/10.1016/j.annals.2005.08.002 
Stepchenkova S, Belyaeva V (2021) The effect of authenticity orientation on existential authenticity and postvisitation intended behavior. J Travel Res 60(2):401-416. https://doi.org/10.1177/0047287519 899989

Stephenson LB, Crete J (2010) Studying political behavior: a comparison of internet and telephone surveys. Int J Pub Opin Res 23(1):24-55. https://doi.org/10.1093/ijpor/edq025

Tsao H-C, Kao H (1994) A dream of red mansions In: Yang H-Y, Yang G (eds) Trans. first ed. Foreign Languages Press, Beijing.

Tussyadiah IP, Wang D, Jung TH, Tom Dieck MC (2018) Virtual reality, presence, and attitude change: Empirical evidence from tourism. Tour Manag 66:140-154. https://doi.org/10.1016/j.tourman.2017. 12.003

Vaismoradi M, Jones J, Turunen H, Snelgrove S (2016) Theme development in qualitative content analysis and thematic analysis. J Nurs Edu Pract. https://doi.org/10.5430/jnep.v6n5p100

van den Bosch R, Taris TW (2014) Authenticity at work: development and validation of an individual authenticity measure at work. J Happiness Stud 15(1):1-18. https://doi.org/10.1007/ s10902-013-9413-3

Wagler A, Hanus MD (2018) Comparing virtual reality tourism to real-life experience: effects of presence and engagement on attitude and enjoyment. Commun Res Rep 35(5):456-464. https://doi.org/ $10.1080 / 08824096.2018 .1525350$

Wang N (1999) Rethinking authenticity in tourism experience. Ann Tour Res 26(2):349-370. https://doi. org/10.1016/S0160-7383(98)00103-0

Wang D, Niu Y, Lu L, Qian J (2015) Tourism spatial organization of historical streets-a postmodern perspective: the examples of Pingjiang Road and Shantang Street, Suzhou, China. Tour Manage 48:370-385. https://doi.org/10.1016/j.tourman.2014.12.007

Wei W (2019) Research progress on virtual reality (VR) and augmented reality (AR) in tourism and hospitality: A critical review of publications from 2000 to 2018. J Hosp Tour Technol 10(4):539-570. https://doi.org/10.1108/JHTT-04-2018-0030

Xu H, Wan X, Fan X (2014) Rethinking authenticity in the implementation of China's heritage conservation: the case of Hongcun Village. Tour Geogr 16(5):799-811. https://doi.org/10.1080/14616688. 2014.963662

Yi X, Lin VS, Jin W, Luo Q (2017) The authenticity of heritage sites, tourists' quest for existential authenticity, and destination loyalty. J Travel Res 56(8):1032-1048. https://doi.org/10.1177/00472 87516675061

Yi X, Fu X, Yu L, Jiang L (2018) Authenticity and loyalty at heritage sites: the moderation effect of postmodern authenticity. Tour Manage 67:411-424. https://doi.org/10.1016/j.tourman.2018.01.013

Yung R, Khoo-Lattimore C (2019) New realities: a systematic literature review on virtual reality and augmented reality in tourism research. Curr Issue Tour 22(17):2056-2081. https://doi.org/10.1080/ 13683500.2017.1417359

Publisher's Note Springer Nature remains neutral with regard to jurisdictional claims in published maps and institutional affiliations. 